\title{
Hyaluronan deposition in islets may precede and direct the location of islet immune-cell infiltrates
}

\author{
Marika Bogdani $^{1}$ (D) Cate Speake ${ }^{2} \cdot$ Mathew J. Dufort $^{3} \cdot$ Pamela Y. Johnson $^{1} \cdot$ Megan J. Larmore $^{4} \cdot$ Anthony J. Day $^{5}$. \\ Thomas N. Wight ${ }^{1}$ • Åke Lernmark ${ }^{6,7}$. Carla J. Greenbaum ${ }^{2}$
}

Received: 18 April 2019 / Accepted: 10 October 2019 / Published online: 6 January 2020

(C) Springer-Verlag GmbH Germany, part of Springer Nature 2020

\begin{abstract}
Aims/hypothesis Substantial deposition of the extracellular matrix component hyaluronan (HA) is characteristic of insulitis in overt type 1 diabetes. We investigated whether HA accumulation is detectable in islets early in disease pathogenesis and how this affects the development of insulitis and beta cell mass.

Methods Pancreas tissue from 15 non-diabetic organ donors who were positive for islet autoantibodies (aAbs) and from 14 similarly aged $\mathrm{aAb}^{-}$control donors were examined for the amount of islet HA staining and the presence of insulitis. The kinetics of HA deposition in islets, along with the onset and progression of insulitis and changes in beta cell mass, were investigated in BioBreeding DRLyp/Lyp rats (a model of spontaneous autoimmune diabetes) from 40 days of age until diabetes onset.

Results Abundant islet HA deposits were observed in pancreas tissues from $n=3$ single- and $n=4$ double-aAb ${ }^{+}$donors (aAb $\left.{ }^{+} \mathrm{HA}^{\text {high }}\right)$. In these seven tissues, the HA-stained areas in islets measured $1000 \pm 240 \mu^{2}$ (mean $\pm \mathrm{SEM}$ ) and were fourfold larger than those from $\mathrm{aAb}^{-}$control tissues. The $\mathrm{aAb}^{+} \mathrm{HA}^{\text {high }}$ tissues also had a greater prevalence of islets that were highly rich in $\mathrm{HA}$ ( $21 \%$ of the islets in these tissues contained the largest HA-stained areas $\left[>2000 \mu \mathrm{m}^{2}\right]$ vs less than $1 \%$ in tissues from $\mathrm{aAb}^{-}$control donors). The amount of HA staining in islets was associated with the number of aAbs (i.e. single- or double-aAb positivity) but not with HLA genotype or changes in beta cell mass. Among the seven $\mathrm{aAb}^{+} \mathrm{HA}^{\text {high }}$ tissues, three from single- and one from double-aAb $\mathrm{b}^{+}$donors did not show any islet immune-cell infiltrates, indicating that $\mathrm{HA}$ accumulates in $\mathrm{aAb}^{+}$donors independently of insulitis. The three $\mathrm{aAb}^{+} \mathrm{HA}^{\text {high }}$ tissues that exhibited insulitis had the largest HA-stained areas and, in these tissues, islet-infiltrating immune cells co-localised with the most prominent HA deposits (i.e. with HA-stained areas $>2000 \mu \mathrm{m}^{2}$ ). Accumulation of HA in islets was evident prior to insulitis in 78-week-old presymptomatic DRLyp/Lyp rats, in which the islet HA-stained area measured $2370 \pm 170 \mu \mathrm{m}^{2}$ (mean $\pm \mathrm{SEM}$ ), which was threefold larger than in 6-week-old rats. This initial islet HA deposition was not concurrent with beta cell loss. Insulitis was first detected in 9-10-week-old rats, in which the HA-stained areas were $4980 \pm 500 \mu^{2}$. At this age, the rats also exhibited a $44 \%$ reduction in beta cell mass. Further enlargement of the HA-positive areas (mean \pm SEM: $7220 \pm 880 \mu \mathrm{m}^{2}$ ) was associated with invasive insulitis. HA deposits remained abundant in the islets of rats with destructive insulitis, which had lost $85 \%$ of their beta cells.

Conclusions/interpretation This study indicates that HA deposition in islets occurs early in type 1 diabetes and prior to insulitis, and points to a potential role of HA in triggering islet immune-cell infiltration and the promotion of insulitis.
\end{abstract}

Electronic supplementary material The online version of this article (https://doi.org/10.1007/s00125-019-05066-7) contains peer-reviewed but unedited supplementary material, which is available to authorised users.

Marika Bogdani

mbogdani@benaroyaresearch.org

1 Matrix Biology Program, Benaroya Research Institute at Virginia Mason, 1201 9th Avenue, Seattle, WA 98101, USA

2 Diabetes Research Program and Clinical Research Center, Benaroya Research Institute at Virginia Mason, Seattle, WA, USA

3 Bioinformatics Department, Benaroya Research Institute at Virginia Mason, Seattle, WA, USA
4 Histology and Imaging Core, University of Washington, Seattle, WA, USA

5 Wellcome Trust Centre for Cell-Matrix Research, University of Manchester, Manchester, UK

6 Department of Medicine, University of Washington, Seattle, WA, USA

7 Present address: Department of Clinical Sciences, Lund University/ CRC, Skåne University Hospital, Malmö, Sweden 


\section{Research in context}

\section{What is already known about this subject?}

- We previously reported that an extracellular matrix rich in hyaluronan $(\mathrm{HA})$ is a prominent feature of insulitis in type 1 diabetes

\section{What is the key question?}

- Does the accumulation of HA take place early in type 1 diabetes and prior to insulitis?

\section{What are the new findings?}

- Large HA deposits are present in islets in a subset of autoantibody $(\mathrm{aAb})^{+}$organ donors, and are the sites where immune cells infiltrate the islets. The abundance of these deposits is associated with the number of aAbs (single or double aAb positivity) but not with HLA genotype

- Islet HA deposits form both in pancreases in which insulitis is not detected and in immune-cell-free islets in pancreases that exhibit insulitis, which indicates that islet immune-cell infiltrates are not required for initial islet HA deposition

- Incipient HA accumulation precedes islet immune-cell infiltration in presymptomatic BioBreeding DRLyp/Lyp rats. Continual amassment of $\mathrm{HA}$ is associated with the appearance of the insulitic cells and positively correlates with the degree of insulitis

How might this impact on clinical practice in the foreseeable future?

- Our findings implicate accumulation of HA as a marker of early disease and as a mediator driving immune cell migration into islets, which opens the door for potential novel therapeutic interventions that target $\mathrm{HA}$ accumulation

Keywords Autoantibodies · Extracellular matrix · Hyaluronan · Insulitis · Islet · Type 1 diabetes

$\begin{array}{ll}\text { Abbreviations } \\ \mathrm{aAb} & \text { Autoantibody } \\ \mathrm{BB} & \text { BioBreeding } \\ \mathrm{ECM} & \text { Extracellular matrix } \\ \mathrm{HA} & \text { Hyaluronan } \\ \text { LCA } & \text { Leucocyte common antigen } \\ \mathrm{SYN} & \text { Synaptophysin }\end{array}$

\section{Introduction}

The process of beta cell damage in type 1 diabetes starts long before the disease becomes overt, and is influenced by both genetic and environmental factors $[1,2]$. The early stage of disease pathogenesis is characterised by islet autoimmunity, marked by two or more of the four currently identified type 1 diabetes-associated islet autoantibodies (aAbs; against insulin, GAD65, islet tyrosine phosphatase 2 [IA-2] or zinc transporter 8 [ZnT8]), followed by increasing beta cell dysfunction and death, and then clinically apparent disease [1, 3-8]. A histopathological hallmark of diabetes at the time of clinical onset is insulitis, an inflammatory cell infiltrate indicating an ongoing immune-cell mediated process in islets that, presumptively, results in beta cell destruction [9-15]. At present, what guides immune-cell trafficking from the blood into islets is not known. Moreover, the initial changes in human islets that trigger the recruitment of immune cells have not been defined.

We have proposed that an increase in the amount of hyaluronan (HA), a major component of the islet extracellular matrix (ECM), takes place early in the natural course of type 1 diabetes, and that HA accumulation promotes islet invasion by immune cells and functional impairment of beta cells [16, 17]. HA, a linear high-molecular-weight polysaccharide, amasses at sites of inflammation and has become recognised as a regulator of several aspects of inflammation, including leucocyte migration, angiogenesis and the generation of inflammatory cytokines [18-20]. Our previous observations of abundant HA in insulin-deficient islets and regions of insulitis in type 1 diabetes establish a link between HA accumulation in islets, beta cell loss and insulitis [16]. However, this association is based on changes in islets resulting from a chronic process that has been ongoing for months to years. Whether islet HA accumulation is an early event in type 1 diabetes pathogenesis and how it influences the development of insulitis is not known. To address this question, we investigated the occurrence and distribution of islet HA deposits in the presence or absence of insulitis in pancreas tissues from non-diabetic $\mathrm{aAb}^{+}$organ donors. In addition, we evaluated the kinetics of HA accumulation in islets concurrently with the extent of islet immune-cell infiltration and changes in beta cell 
mass in presymptomatic BioBreeding (BB) DRLyp/Lyp rats during the progression to hyperglycaemia.

\section{Methods}

Donors and tissue procurement Pancreas tissues samples from non-diabetic organ donors were obtained through the Network for Pancreatic Organ Donors with Diabetes (nPOD). Samples were from $n=10$ single-aAb ${ }^{+}$and $n=5$ double-aAb ${ }^{+}$donors, and $n=14$ similarly aged control $\mathrm{aAb}^{-}$ donors. Clinical characteristics of the donors are shown in electronic supplementary material (ESM) Table 1 (note that this study did not involve isolated human islets, but paraffin sections prepared from formalin-fixed paraffin-embedded pancreas tissues from organ donors). For each donor, we randomly sampled six paraffin blocks from different regions of the pancreas. The pancreas tissues are referred to, henceforth, as 'tissues'. All the experiments were carried out with the approval of the Institutional Review Board of the Benaroya Research Institute. The investigators were not blind to the group assignment since the tissues were obtained as they became available, and the donor aAb status was known by the investigators. However, the investigators were blind to $\mathrm{aAb}$ status during data collection.

BB DR rats The $\mathrm{BB}$ rat model of autoimmune diabetes shares characteristics common to human disease, including spontaneous hyperglycaemia, ketoacidosis, genetic susceptibility and insulitis [21]. Male and female BB DR+/+, DRLyp/+, and DRLyp/Lyp rats [22] were obtained from A. Lernmark at the University of Washington (Seattle, WA, USA). The rats were housed in a specific-pathogen-free facility at the University of Washington on a 12-h light/dark cycle and were fed a regular diet (Harlan Teklad, Madison, WI, USA) and given water ad libitum. Diabetes develops spontaneously by 12 weeks of age in DRLyp/Lyp rats, while the diabetesresistant $(\mathrm{DR}+/+$ and $\mathrm{DR} L y p /+)$ rats remain diabetes-free throughout life $[22,23]$. The colony was maintained by intercrossing DRLyp/+ rats. These crosses generated DRLyp/ Lyp rats as well as $\mathrm{DR} L y p /+$ and $\mathrm{DR}+/+$ controls. The $\mathrm{DR} L y p /+$ and $\mathrm{DR}+/+$ control rats had similar body weights, glucose levels and islet morphology at all ages. The body weight and blood glucose for each individual rat was recorded daily, from 40 days of age until DRLyp/Lyp rats became diabetic (blood glucose levels $\geq 14 \mathrm{mmol} / \mathrm{l}$ ). Rat pancreases were processed for histological analysis or hormone assay. All animal studies were approved by the Institutional Animal Care and Use Committees of the University of Washington and the Benaroya Research Institute.

Histochemistry and immunohistochemistry Staining methodologies were performed as previously described [17]. Serial sections were prepared from all the paraffin blocks. Sections were stained for HA using a biotinylated HA binding protein prepared from cartilage [24]. The primary antibodies used for immunohistochemistry are listed in ESM Table 2. The primary and secondary antibodies were diluted in PBS (ThermoFisher, Waltham, MA, USA). Positive and negative controls were included in each staining experiment. Sections were examined using a Leica DM IRB microscope (Wetzlar, Germany), and images were acquired using a Spot Xplorer camera and imaging software (Sterling Heights, MI, USA).

Morphometric analysis and quantification Whole-section bright-field imaging was performed as previously described $[17,23]$. Islets were identified by their staining for synaptophysin (SYN). Thirty per cent of the human islets were sampled according to assumption-free systematic uniform random sampling (based on our pilot studies, which indicate that this sampling results in a coefficient of error $<2 \%$ ). We classified $\mathrm{HA}^{+}$areas in islets using an established categorisation scheme with the following categories: $\leq 100$, 101-500, 501-1000, 1001-2000, and $>2000 \mu \mathrm{m}^{2}$ per islet $[17,25,26]$. Tissues from $\mathrm{aAb}^{+}$donors, with a mean islet HA-stained area significantly larger than that of the $\mathrm{aAb}^{-}$ controls, were defined as $\mathrm{aAb}^{+} \mathrm{HA}^{\text {high }}$ or as having $\mathrm{HA}$ deposits, while tissues with islet HA-stained areas that were similar in size to those of the controls were defined as $\mathrm{aAb}^{+} \mathrm{HA}^{\text {low }}$.

Evaluation of islet immune-cell infiltrates Sections were stained for leucocyte common antigen (LCA) and SYN to detect islet-infiltrating immune cells. All islets present in the sections were examined. Islets were counted along with the number of $\mathrm{LCA}^{+}$cells in contact with endocrine cells $[17,22]$. Human islet immune-cell infiltrates were evaluated by determining: (1) the percentage of islets with $\mathrm{LCA}^{+}$ cells adjacent to endocrine cells; and (2) the number of $\mathrm{LCA}^{+}$cells per islet that were adjacent to endocrine cells. Tissues exhibiting $\geq 15 \mathrm{LCA}^{+}$cells in contact with endocrine cells per islet $[9,27]$ were defined as $\operatorname{LCA}^{\text {high }}$. In $\mathrm{DRLyp/Lyp}$ rats, insulitis is a continuum from scarce to numerous immune cells. Immune cells first appear at the islet periphery and subsequently invade the whole islet. In these rats, insulitis was evaluated according to the presence and the extent of islet $\mathrm{LCA}^{+}$cell infiltration and was graded as follows: grade 0 , no infiltration; grade $1, \mathrm{LCA}^{+}$cells present around islets and within the islets in $\leq 25 \%$ of the islet area; grade $2, \mathrm{LCA}^{+}$cells occupying $25-75 \%$ of the islet area; grade $3, \mathrm{LCA}^{+}$cells infiltrating $\geq 75 \%$ of the islet or the islets are devoid of beta cells. Each islet in an individual rat was examined once and assigned an insulitis grade; the grade of highest prevalence determined the insulitis grade for that rat (ESM Table 3). Control $\mathrm{DRLyp} /+$ and $\mathrm{DR}+/+$ rats do not develop insulitis. 
Quantification of islet mass, beta cell mass, proliferation and apoptosis One section for each of the paraffin blocks sampled per human pancreas was stained for Ki67/insulin to determine beta cell proliferation rate and to measure the relative insulin ${ }^{+}$ area. Four sections per pancreas were stained for TUNEL/ insulin to determine the apoptosis rate. The TUNEL stain (Millipore, Burlington, MA, USA) was performed according to the manufacturer's instructions. For each rat, consecutive pancreas sections were stained for SYN (eight sections per rat, $400 \mu \mathrm{m}$ apart) and insulin (eight sections per rat, $400 \mu \mathrm{m}$ apart) to measure the relative pancreas islet and beta cell areas at $100 \%$ sampling using Visiopharm software (Hoersholm, Denmark). The relative positive areas were then multiplied by the pancreas weight to determine islet or beta cell mass.

Statistical analysis Data are expressed as mean \pm SEM of $n$ independent measurements. The significance of the difference between two or more groups of data was evaluated using the Mann-Whitney $U$ test, Kruskal-Wallis test or ANOVA. Correlation analysis was performed using the nonparametric Spearman's rank correlation test. A $p$ value of less than 0.05 was considered statistically significant. All analyses were performed using GraphPad Prism version 7.00 for Windows (GraphPad Software, San Diego, CA, USA).

\section{Results}

\section{Abundant islet $\mathrm{HA}$ deposits form in a subset of $\mathrm{aAb}^{+}$donors} While HA was detectable extracellularly in islets from all tissues, islets from $\mathrm{aAb}^{+}$donors exhibited HA deposits, defined by the greater areas of HA staining vs controls (Fig. 1). Examination of 4598 islets from $14 \mathrm{aAb}^{-}$and 5482 islets from $15 \mathrm{aAb}^{+}$donors indicated a 2.8-fold larger islet HA-stained area in the $\mathrm{aAb}^{+}$group. This difference was due to a higher occurrence of larger areas of HA staining $\left(>500 \mu \mathrm{m}^{2}\right)$ and a lower occurrence of smaller HA-stained areas $\left(\leq 500 \mu^{2}\right)$ than in $\mathrm{aAb}^{-}$controls $(p<0.001$, one-way ANOVA). We used the range of HA-stained areas in the control samples to define an upper cut-off value for 'normal' HA staining, set at $3 \mathrm{SD}$ above the mean of the controls, as it should include $>99 \%$ of values typical of $\mathrm{aAb}^{-}$controls. Dividing the $15 \mathrm{aAb}^{+}$donors using this threshold yielded two distinct groups (Fig. 2e, ESM Fig. 1 and ESM Fig. 2a). One group, consisting of eight $\mathrm{aAb}^{+}$donors $\left(\mathrm{aAb}^{+} \mathrm{HA}^{\text {low }}\right)$ was not different from the $\mathrm{aAb}^{-}$controls ( $p>0.05$, Mann-Whitney $U$ test), while the other group, consisting of seven $\mathrm{aAb}^{+}$donors $\left(\mathrm{aAb}^{+} \mathrm{HA}^{\text {high }}\right)$ had HA deposits in their islets. These seven donors were at different stages of islet autoimmunity since three of these were single $\mathrm{aAb}^{+}$and four were double $\mathrm{aAb}^{+}$. In tissue from these donors, the mean islet HA-stained area was fourfold larger than in the other donors $\left(1000 \pm 240 \mu \mathrm{m}^{2}\right.$ vs $250 \pm 20 \mu \mathrm{m}^{2}$; Fig. $\left.2 \mathrm{e}\right)$. The $\mathrm{aAb}^{+} \mathrm{HA}^{\text {high }}$ tissues also showed a greater prevalence of islets highly rich in HA $(21 \%$ of these islets contained the largest HA-stained areas [of $>2000 \mu^{2}$ ] vs $<1 \%$ in the controls (Fig. 2f). Moreover, in these tissues, islet $\mathrm{HA}^{+}$areas measuring 6000 to $28,000 \mu \mathrm{m}^{2}$ were frequently observed, while such areas were not present in the $\mathrm{aAb}^{-}$controls and $\mathrm{aAb}^{+} \mathrm{HA}^{\text {low }}$ tissues (ESM Fig. 1).

We found a positive association between the amount of islet HA staining and the number of aAbs, but there was no association between the amount of islet HA staining and donor age (Fig. 2e,f and ESM Fig. 2b). The islet HA-stained areas in tissues from single-aAb $\mathrm{b}^{+}$donors were, on average, 1.6-fold greater than in the $\mathrm{aAb}^{-}$controls. This increase in size was attributable to the HA abundance in three single-aAb ${ }^{+}$ donors who exhibited 2.7- and 3.4-fold larger islet HAstained areas vs the $\mathrm{aAb}^{-}$group or the other seven single$\mathrm{aAb}^{+}$donors, respectively $(p<0.01)$. Overall, the double$\mathrm{aAb}^{+}$group also exhibited larger amounts of islet HA staining compared with the single- $\mathrm{AAb}^{+}$or $\mathrm{aAb}^{-}$groups. This was a result of the prominent $\mathrm{HA}$ deposition in four of the five donors in this group, which resulted in islet $\mathrm{HA}^{+}$areas that were four- and fivefold larger than the single- $\mathrm{AAb}^{+}$donors or $\mathrm{aAb}^{-}$control group, respectively $(p<0.01)$. The increase in islet $\mathrm{HA}$ area in the $\mathrm{aAb}^{+} \mathrm{HA}^{\text {high }}$ tissues was not determined by islet size. Overall, the mean islet areas in $\mathrm{aAb}^{+}$donors were within the range of $\mathrm{aAb}^{-}$controls (ESM Fig. 3).

\section{Islet HA deposits form in the absence of insulitis and are the sites of immune-cell infiltrates}

Among the seven $\mathrm{aAb}^{+} \mathrm{HA} \mathrm{A}^{\text {high }}$ tissues, three from single-aAb donors and one from a double-aAb ${ }^{+}$donor did not show insulitis (Fig. 3). The scarce islet-associated $\mathrm{LCA}^{+}$cells present in these four HA-rich tissues occurred in single units. Insulitis was detected in the three remaining tissues from donors positive for two aAbs (Fig. 3c,d,g-i). In these three $\mathrm{aAb}^{+} \mathrm{HA}^{\text {high }} \mathrm{LCA}^{\text {high }}$ tissues, HA had accumulated in the majority of the islets (Fig. 4d and ESM Fig. 4a). However, $\mathrm{LCA}^{+}$cells were located in only $13 \%, 14 \%$ and $28 \%$ of the islets in each of these tissues (Fig. 3i). The markedly lower prevalence of islets with $\mathrm{LCA}^{+}$cells vs that of HA-rich islets indicates that HA accumulation progresses independently of immune-cell infiltration, even in tissues that eventually develop insulitis. Further assessment of islet HA quantity in relation to insulitis in the three $\mathrm{aAb}^{+} \mathrm{HA}^{\text {high }} \mathrm{LCA}^{\text {high }}$ tissues revealed that the insulitis-free islets contained less HA staining than neighbouring islets with insulitis (3.4-fold), yet more than the islets in the other four $\mathrm{aAb}^{+} \mathrm{HA}^{\text {high }}$ tissues (2.4-fold; see ESM Fig. 4b). Furthermore, the islet-infiltrating immune cells were located almost exclusively in the islets with substantial amounts of islet HA deposits (Fig. 4 and ESM Fig. 4a). In the three $\mathrm{aAb}^{+} \mathrm{HA}^{\text {high }} \mathrm{LCA}^{\text {high }}$ tissues, about one third of the islets exhibited HA-stained areas larger than $2000 \mu \mathrm{m}^{2}$ and $60 \%$ of 

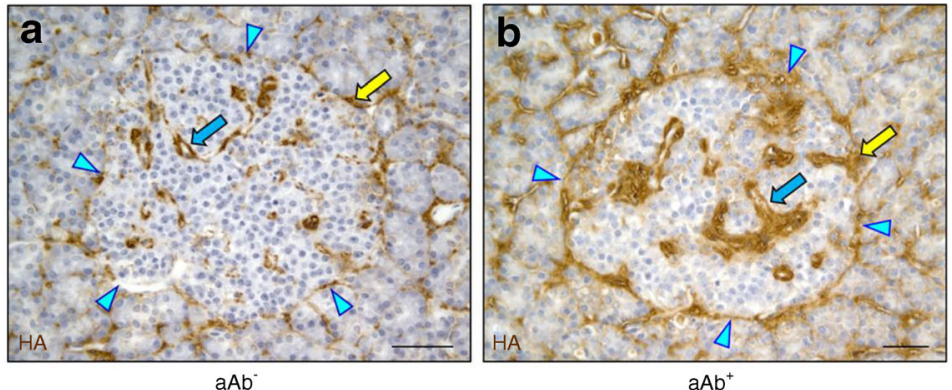

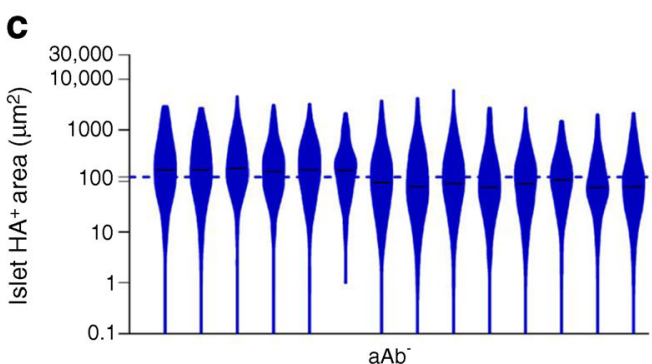

Fig. 1 Islet HA deposits in $\mathrm{aAb}^{+}$donors. HA staining (brown) in islets from (a) $\mathrm{aAb}^{-}$and (b) $\mathrm{aAb}^{+}$donors. Yellow arrows indicate $\mathrm{HA}$ at the islet periphery, while blue arrows indicate HA within the islet. Arrowheads point to the islet border. Scale bars, $50 \mu \mathrm{m}$. (c, d) Violin

these hosted immune cells. By contrast, such areas were found in only $8 \%$ of the islets in the four $\mathrm{aAb}^{+} \mathrm{HA}^{\text {high }}$ tissues without insulitis and their mean size was significantly smaller than in the $\mathrm{aAb}^{+} \mathrm{HA}^{\text {high }} \mathrm{LCA}^{\text {high }}$ tissues $\left(3200 \pm 800 \mu \mathrm{m}^{2}\right.$ vs $6600 \pm$ $\left.4700 \mu \mathrm{m}^{2} ; p<0.001\right)$. In the three $\mathrm{aAb}^{+} \mathrm{HA}^{\text {high }} \mathrm{LCA}^{\text {high }}$ tissues, $\mathrm{CD} 8^{+}$and $\mathrm{CD}^{+}$cells were frequently found in islets with $\mathrm{LCA}^{+}$cells (ESM Fig. $4 \mathrm{c}$ ). Scarce $\mathrm{CD} 20^{+}$or $\mathrm{CD} 11 \mathrm{c}^{+}$cells were detected (in 'Donor 1' only), and were observed in the regions of insulitis, together with other immune cells (ESM Fig. 4c). These data may indicate that cells from both myeloid and lymphoid lineage might be attracted by islet HA. The lower frequency of $\mathrm{CD} 20^{+}$and $\mathrm{CD} 11 \mathrm{c}^{+}$cells vs that of $\mathrm{CD} 68^{+}$and $\mathrm{CD}^{+}$cells may indicate that occurrence of the former may be determined by a specific composition of the HA-rich islet ECM and/or the presence of other immune-cell types in islets.

The formation of large HA deposits in the three tissues with insulitis was not associated with greater numbers of $\mathrm{LCA}^{+}$cells in the non-islet region compared with control tissues. Also, the relative percentage of $\mathrm{HA}^{+}$areas in the non-islet compartment in the $\mathrm{aAb}^{+} \mathrm{HA}^{\text {high }}$ group overall were not significantly different from those in the control group (ESM Fig. 2c,d).

Relationship between human islet $\mathrm{HA}$ and beta cell mass The formation of $\mathrm{HA}$ deposits in islets of $\mathrm{aAb}^{+}$donors was not associated with changes in the size of the beta cell population (Fig. 5a-c). Apoptotic cells with TUNEL ${ }^{+}$nuclei were not detected in the endocrine compartment in any of the tissues from either the $\mathrm{aAb}^{-}$or $\mathrm{aAb}^{+}$groups. Also, the rate of beta cell proliferation did not differ between these two groups $(0.1 \pm$ d

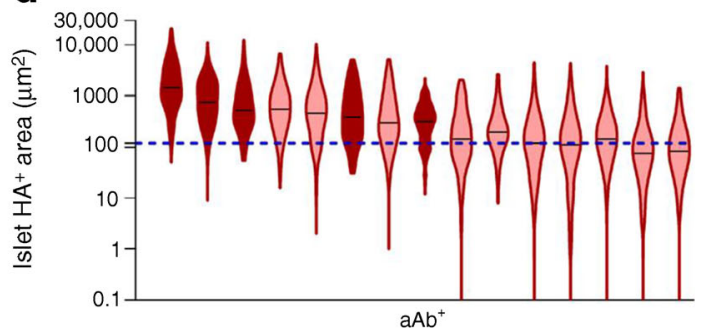

plots of $\mathrm{HA}^{+}$areas measured in islets from each donor for $\mathrm{aAb}^{-}$donors (c) and $\mathrm{aAb}^{+}$donors (d; light red, single- $\mathrm{aAb}^{+}$; dark red, double- $\mathrm{aAb}^{+}$). Islet $\mathrm{HA}^{+}$areas are shown on $\log _{10}$ scale. The dotted horizontal lines indicate the median of $\mathrm{HA}^{+}$area in the control $\mathrm{aAb}^{-}$group

$0.1 \%$ in both). Beta cell mass varied among both $\mathrm{aAb}^{-}$and $\mathrm{aAb}^{+}$donors and was not related to the extent of HA staining. Interestingly, there was little variation in the size of the relative pancreas insulin ${ }^{+}$areas between the two groups, indicating that much of the variability in beta cell mass was due to differences in pancreas weight rather than islet density (Fig. 5d).

Islet HA deposits form in the presence of aAbs but are not HLA-related Previous work indicated that the presence of islet aAbs is HLA-associated, while the progression from $\mathrm{aAb}$ positivity to clinical disease is not $[28,29]$. Therefore, we next examined the extent of islet HA deposition in relation to HLA. Islets from two of nine donors with the HLA haplotype $D R 4$ $D Q 8(D R B 1 * 04-D Q A 1 * 0301-D Q B 1 * 0302)$, which is strongly associated with type 1 diabetes [30,31], had substantial amounts of HA staining. Tissues from three of 12 donors with HLA haplotypes often considered protective for type 1 diabetes $(D R B 1 * 0401-D Q A 1 * 0301-D Q B 1 * 0301, D R B 1 * 1501$ $D Q A 1 * 0102-D Q B 1 * 0603$ and $D R B 1 * 0401-D Q A 1 * 0301$ $D Q B 1 * 0301)$ and from two of seven donors with HLA haplotypes conferring neutral risk $(D R B 1 * 0101-D Q A 1 * 0101$ $D Q B 1 * 0501$ and $D R B 1 * 0701-D Q A 1 * 0201-D Q A 2 * 0201$ ) also exhibited larger $\mathrm{HA}^{+}$areas vs controls (ESM Fig. 5 and ESM Table 1). Thus, overall, the presence of the HA-stained deposits was not associated with HLA haplotype.

In summary, as illustrated in Fig. 6, a subset of single- and double-aAb ${ }^{+}$donors (donors 1-7) showed prominent islet HA deposits. The HA-rich tissues containing the largest quantities of islet HA (donors 1-3) exhibited insulitis. Tissues from the 

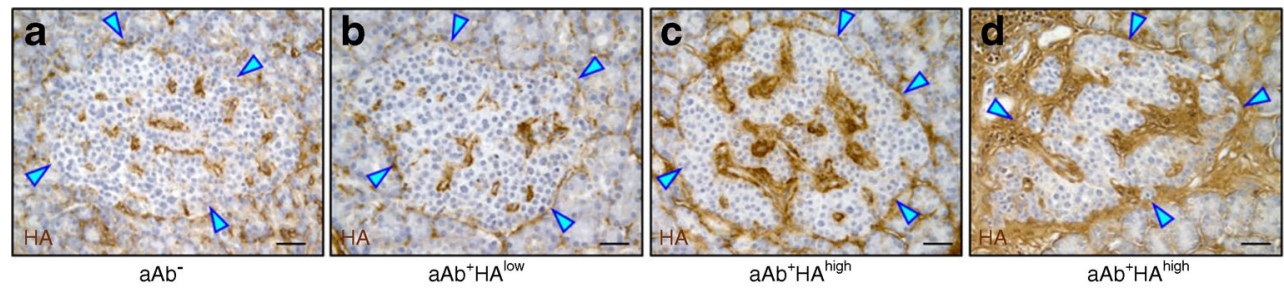
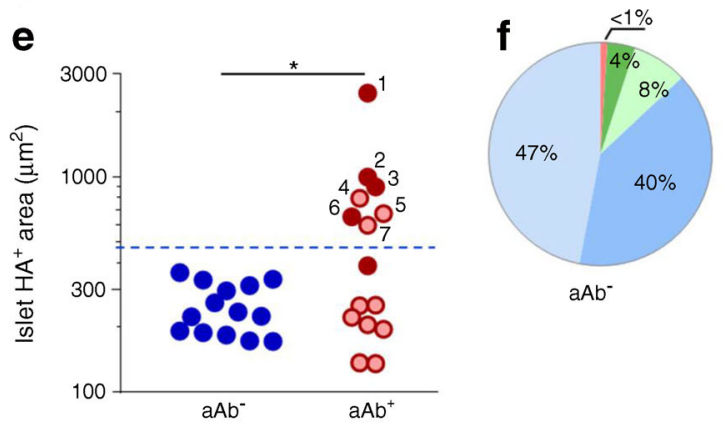

Fig. 2 HA accumulates in islets from a subset of $\mathrm{aAb}^{+}$donors. HA staining (brown) in islets from (a) $\mathrm{aAb}^{-},(\mathbf{b}, \mathbf{c})$ single- $\mathrm{aAb}^{+}$and (d) double- $\mathrm{aAb}^{+}$donors. Arrowheads point to the islet border. Scale bars, $50 \mu \mathrm{m}$. (e) Morphometric quantification of islet $\mathrm{HA}^{+}$areas, shown on a $\log _{10}$ scale. Each circle denotes an individual donor; blue, $\mathrm{aAb}^{-}$; light red, single- $\mathrm{aAb}^{+}$; dark red, double-aAb ${ }^{+}$. Data are mean values of islet $\mathrm{HA}^{+}$ areas for each individual donor. The numbers (1-7) indicate the $\mathrm{aAb}^{+} \mathrm{HA}^{\text {high }}$ tissues ranked according to the size of islet $\mathrm{HA}^{+}$areas. The dotted horizontal line indicates the upper cut-off value (mean of $\mathrm{HA}^{+}$

other $\mathrm{aAb}^{+}$donors (donors $8-15$ ), who were mostly single $\mathrm{aAb}^{+}$, did not exhibit insulitis and did not differ from the $\mathrm{aAb}^{-}$control donors with respect to the quantities and distribution of islet HA, or beta cell mass (ESM Fig. 6).

\section{Islet HA deposition precedes insulitis in presymptomatic} DRLyp/Lyp rats The DRLyp/Lyp rat islets were insulitic-cell free during the first 8 weeks of age (insulitis grade 0; ESM
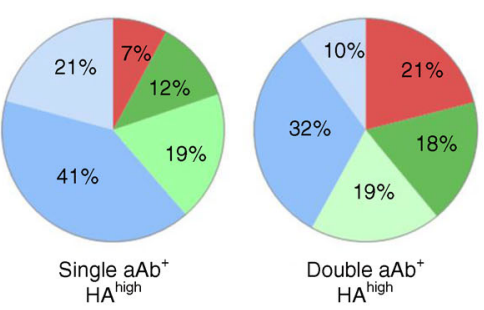

$$
\begin{aligned}
& \text { Islet } \mathrm{HA}^{+} \text {area }\left(\mathrm{um}^{2}\right) \text { size category } \\
& \begin{array}{llllll}
0 & 100 & 500 & 1000 & 2000 & 28,000
\end{array}
\end{aligned}
$$

area in $\mathrm{aAb}^{-}$control $+3 \mathrm{SD}$ ). In total, 4598, 3210 and 2272 islets from $a A b-$, single- $\mathrm{aAb}^{+}$and double- $\mathrm{aAb}^{+}$donor tissues were analysed, respectively. (f) Islet $\mathrm{HA}^{+}$area size distribution. The pie charts represent the percentage of islets with $\mathrm{HA}^{+}$areas falling within each of the $\mathrm{HA}^{+}$area size categories. Islets were analysed in $\mathrm{aAb}^{-}$tissues $(n=4598$ islets $)$ and in $\mathrm{aAb}^{+} \mathrm{HA}^{\text {high }}$ tissues from $n=3$ single- $\mathrm{aAb}^{+}$donors ( $n=982$ islets) and $n=4$ double $-\mathrm{aAb}^{+}$donors $(n=1828$ islets). $* p<0.001$, single$\mathrm{aAb}^{+} \mathrm{HA}^{\text {high }}$ vs controls, and double-aAb ${ }^{+} \mathrm{HA}^{\text {high }}$ vs single- $\mathrm{aAb}^{+} \mathrm{HA} \mathrm{A}^{\text {high }}$ or controls; Mann-Whitney $U$ test

Table 3). The insulitic infiltrates appeared at 9-10 weeks of age (grade 1, inaugural insulitis). Subsequently, these infiltrates gradually expanded around and within islets (grade 2, invasive insulitis), and then spread throughout them (grade 3, destructive insulitis). In this last stage, the islets showed massive beta cell loss (ESM Fig. 7a,b), which typically leads to hyperglycaemia within 24-48 h [22, 23]. We first examined whether HA accumulates in islets prior to the appearance of insulitic cells, and

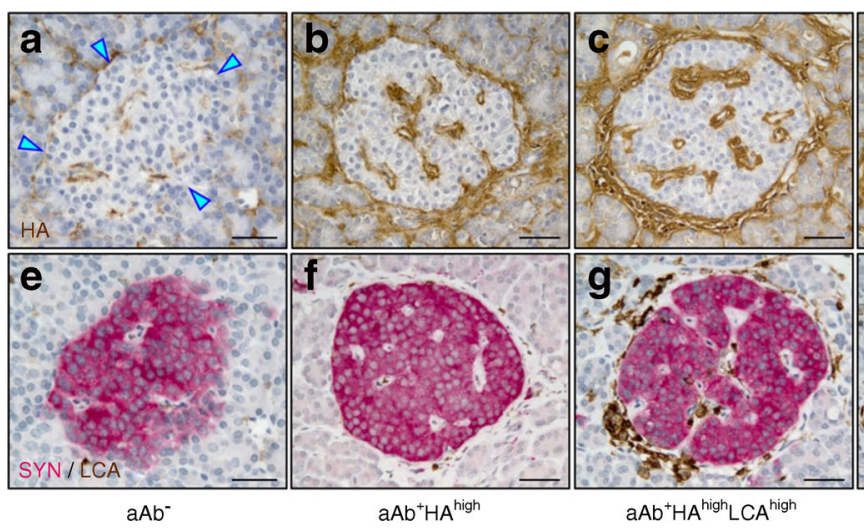

Fig. 3 Islet HA accumulation takes place in the absence of insulitis. $\mathrm{HA}$ staining (brown) in islets from (a) $\mathrm{aAb}^{-}$and (b-d) $\mathrm{aAb}^{+}$donors. Arrowheads point to the islet border. The area of insulitis in (d) is shown magnified in the inset. (e-h) Adjacent sections of the islets shown in (ad), respectively, stained for LCA (brown) and SYN (red). Scale bars, $50 \mu \mathrm{m}$. (i) Prevalence of islets with $\mathrm{LCA}^{+}$cell infiltrates plotted as a
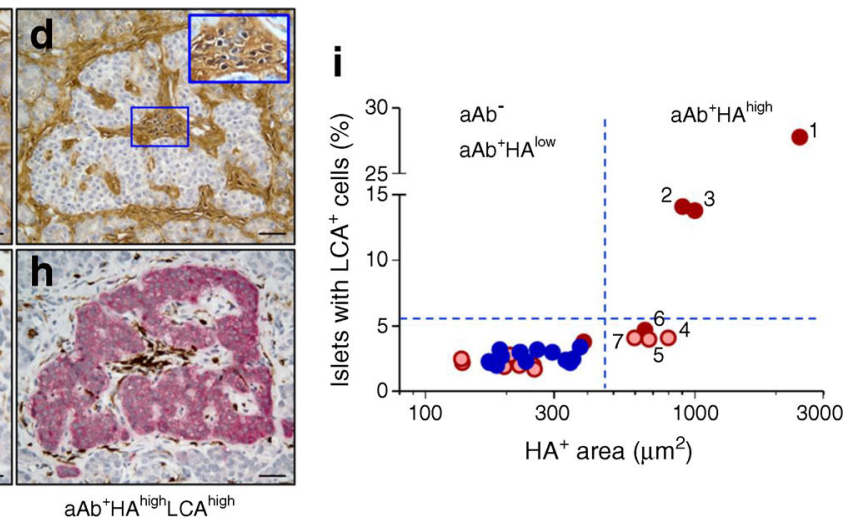

function of islet $\mathrm{HA}^{+}$areas, shown on a $\log _{10}$ scale. Each circle denotes mean values for an individual donor. The dotted lines indicate the upper cut-off values (mean $+3 \mathrm{SD}$ ) of the measurements obtained from the $\mathrm{aAb}^{-}$controls. The numbers (1-7) indicate the $\mathrm{aAb}^{+} \mathrm{HA}^{\text {high }}$ tissues ranked according to the size of islet $\mathrm{HA}^{+}$areas. Blue, $\mathrm{aAb}^{-}$; light red, single$\mathrm{aAb}^{+}$; dark red, double- $\mathrm{aAb}^{+}$ 

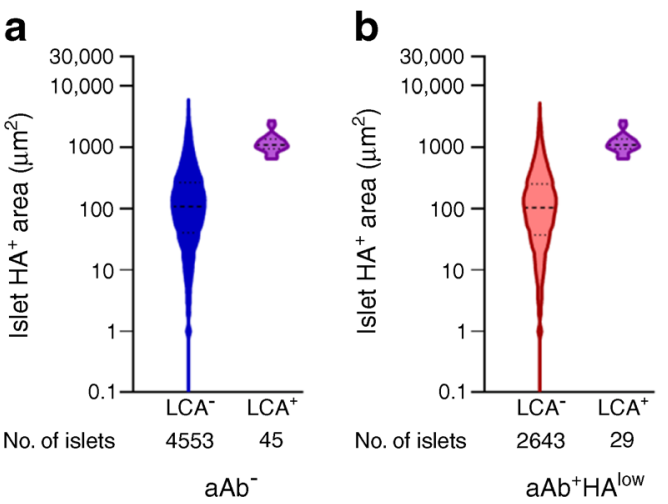

Fig. 4 Insulitis occurs exclusively in the islet regions containing the largest HA deposits. Violin plots of $\mathrm{HA}^{+}$areas in islets without $\left(\mathrm{LCA}^{-}\right)$or with $\left(\mathrm{LCA}^{+}\right)$immune cells for the (a) $\mathrm{aAb}^{-}$, (b) $\mathrm{aAb}^{+} \mathrm{HA}^{\text {low }}$, (c) $\mathrm{aAb}^{+} \mathrm{HA}^{\text {high }}$ and (d) $\mathrm{aAb}^{+} \mathrm{HA}^{\text {high }} \mathrm{LCA}^{\text {high }}$ tissues. Islet $\mathrm{HA}^{+}$areas are

then assessed the initiation and progression of insulitis, and beta cell mass, as a function of the amount of islet HA in DRLyp/Lyp rats during the progression to hyperglycaemia.

At 6 weeks of age, the quantities of islet HA staining in the DRLyp/Lyp rats did not differ from those in the DRLyp/+ (ESM Fig. 7c) or DR+/+ controls (data not shown). In addition, the distribution of islet HA staining did not differ between the groups (data not shown). Islet HA deposits had developed both around and within islets in 7-8-week-old DRLyp/Lyp rats, which exhibited threefold and 2.4-fold larger islet $\mathrm{HA}^{+}$areas compared with 6-week-old DRLyp/Lyp and control rats, respectively (7-8-week-old DRLyp/Lyp, $2370 \pm$ $170 \mu^{2}$; 6-week-old DRLyp/Lyp, $800 \pm 50 \mu \mathrm{m}^{2}$; control, $1010 \pm 40 \mu \mathrm{m}^{2}$; Fig. 7, ESM Fig. 7c and ESM Fig. 8a,b). However, these 7-8-week-old DRLyp/Lyp rats did not show any islet-associated $\mathrm{LCA}^{+}$cells (Fig. 7). Thus, in presymptomatic DRLyp/Lyp rats, islet HA deposits form before the appearance of insulitic cells.

In the 9-10-week-old DRLyp/Lyp rats, islet HA-stained areas were, on average, twice as large as those of their 7-8week-old DRLyp/Lyp littermates $\left(4980 \pm 500 \mu \mathrm{m}^{2}\right.$ vs $2370 \pm$ $170 \mu^{2}$; Fig. 7k), while the $\mathrm{SYN}^{+}$islet areas were smaller (ESM Fig. 8f). This increase in HA area size was due to a higher prevalence of islets rich in HA and the formation of large HA deposits measuring $8000-16,000 \mu \mathrm{m}^{2}$, which were not present in younger rats (data not shown). At this age, the first insulitic cells appeared and were embedded within the largest HA accumulations. This suggests that HA-rich areas are the sites of immune-cell entry into islets. The islet $\mathrm{HA}^{+}$ areas were larger in DRLyp/Lyp rats at 10-11 weeks of age vs at 9-10-weeks of age (1.5-fold: $7220 \pm 880 \mu^{2}$ vs $4980 \pm$ $500 \mu \mathrm{m}^{2}$; Fig. 7) and measured up to $30,000 \mu \mathrm{m}^{2}$, indicating a massive deposition of islet HA. This was associated with exacerbation of insulitis, since most islets exhibited a higher degree of immune-cell infiltration.

The initial accumulation of HA in 7-8-week-old DRLyp/ Lyp rat islets was not associated with a significant loss of beta
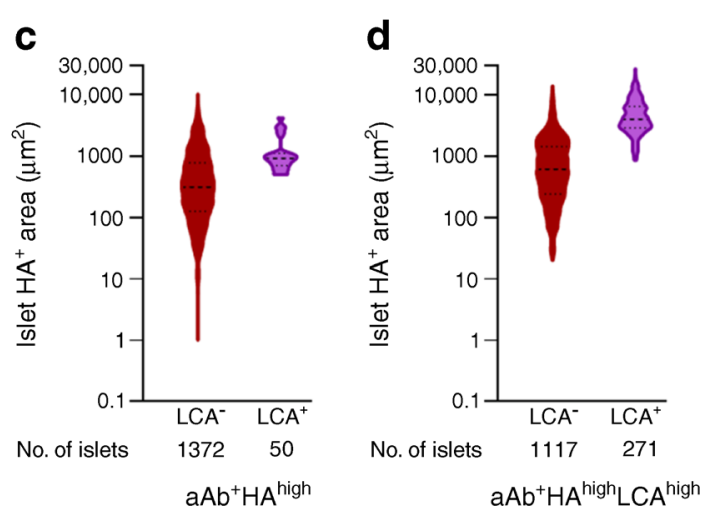

shown on a $\log _{10}$ scale. The total number of $\mathrm{LCA}^{-}$or $\mathrm{LCA}^{+}$islets in each group is indicated. $\mathrm{LCA}^{+}$cells/100 islets: $3 \pm 1$ in (a) and (b); $5 \pm 2$ in (c); $47 \pm 36$ in (d)

cells (Fig. 7 and ESM Fig. 8b,c; $p>0.05$, Spearman's rank correlation test). In rats exhibiting abundant islet HA staining
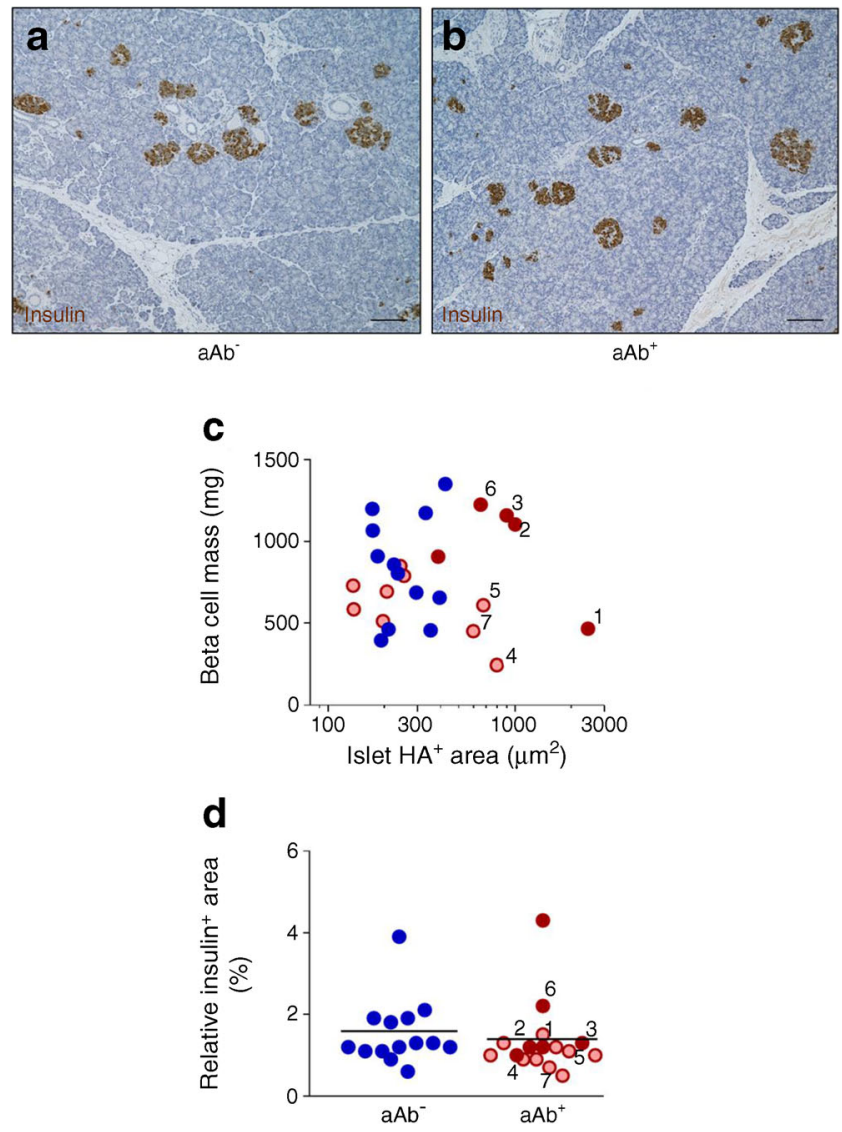

Fig. 5 Relationship between islet HA and beta cell mass. Immunohistochemical staining for insulin (brown) in islets from (a) control $\mathrm{aAb}^{-}$and (b) $\mathrm{aAb}^{+} \mathrm{HA}^{\text {high }}$ tissues. Scale bars, $100 \mu \mathrm{m}$. (c) Individual measurements of beta cell mass plotted as a function of islet $\mathrm{HA}^{+}$area, shown on a $\log _{10}$ scale. (d) Insulin ${ }^{+}$area relative to pancreas section area. Data are presented as the mean values of measurements for each individual donor. In (d), the horizontal lines represent the mean value in each group. The numbers (1-7) indicate the $\mathrm{aAb}^{+} \mathrm{HA}^{\text {high }}$ tissues ranked according to the size of islet $\mathrm{HA}^{+}$areas. Blue, $\mathrm{aAb}^{-}$; light red, single-aAb ${ }^{+}$; dark red, double-aAb ${ }^{+}$ 
a

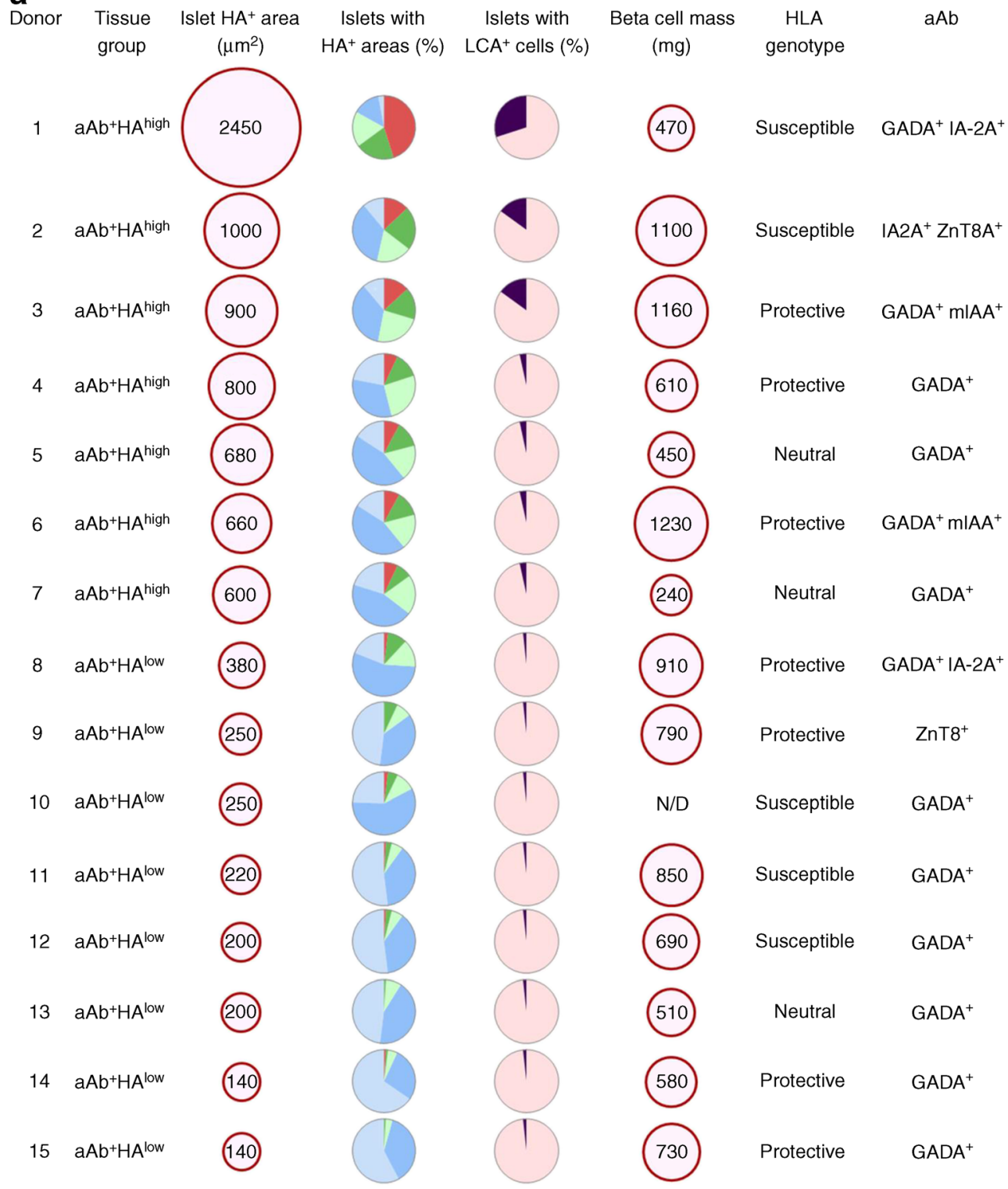

Islets with $\mathrm{LCA}^{+}$cells (\%)

b

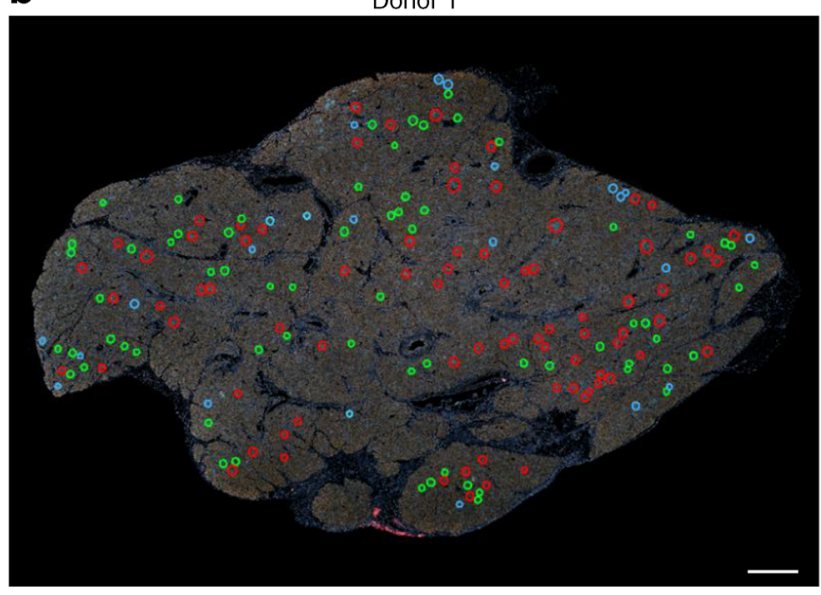

Donor 13

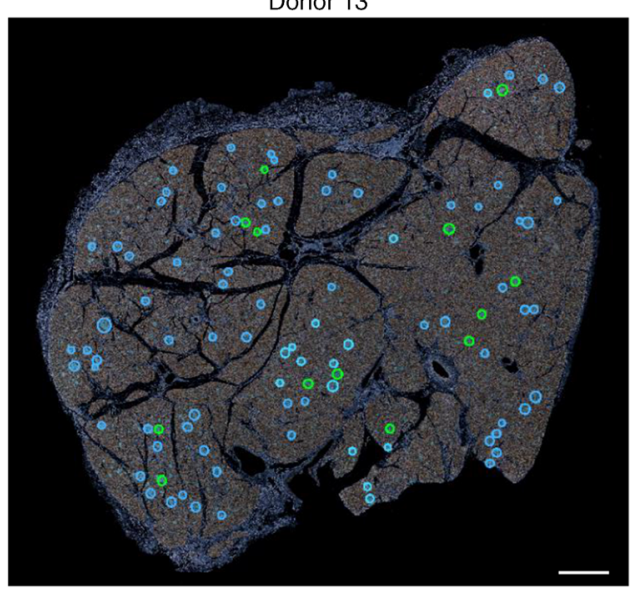


4 Fig. 6 (a) Islet $\mathrm{HA}^{+}$areas, insulitis and beta cell mass in individual $\mathrm{aAb}^{+}$ donors. Islet $\mathrm{HA}^{+}$areas are shown as mean values obtained from the islets examined in each pancreas. Between 250 and 560 islets were analysed per pancreas. For 'islet $\mathrm{HA}^{+}$area' and 'beta cell mass', the size of each red circle is proportional to the mean value, which is indicated within the circle. The pie charts represent the percentage of islets with $\mathrm{HA}^{+}$areas falling within each of the $\mathrm{HA}^{+}$area size categories or the percentage of islets with $\mathrm{LCA}^{+}$cells. HLA genotype and aAb status are also shown for each donor. See ESM Fig. 6 for further analyses. (b) Whole slide images of pancreas tissue sections from donor $1\left(\mathrm{aAb}^{+} \mathrm{HA}^{\text {high }}\right)$ and donor 13 $\left(\mathrm{aAb} \mathrm{HA}^{+} \mathrm{How}^{\text {low }}\right.$. The blue, green, and red circles show the islet border and the indicate islets with HA-stained areas $\leq 500 \mu^{2}, 501-2000 \mu^{2}$ and $>2000 \mu \mathrm{m}^{2}$, respectively. Scale bars, $2000 \mu \mathrm{m}$. N/D, not determined

and grade 1 insulitis, the beta cell mass was reduced to $55 \%$ of that in the controls. With further expansion of the HA deposits and progression to invasive insulitis, the size of the beta cell population continued to decrease. HA remained abundant in rats with destructive insulitis, which had lost $60 \%$ of their islet mass as compared with DRLyp/Lyp rats with grade 0 insulitis $(1 \pm 0.3 \mathrm{mg}$ vs $2.5 \pm 1 \mathrm{mg} ; p<0.01)$ and $85 \%$ of beta cells (ESM Fig. 8c-e).

\section{Discussion}

HA is a major component of the ECM that amasses in chronic inflammatory lesions, where HA exerts proinflammatory effects as a key regulator of leucocyte recruitment to the site of injury [19, 20, 32-34]. Our previous observation of abundant HA in human islets and regions of insulitis in type 1 diabetes implicated HA in the pathogenesis of disease [17]. Here, we investigated whether the accumulation of HA in islets is an early and critical step in the pathogenetic process of insulitis.

We report that HA deposits form in islets in a subset of $\mathrm{aAb}^{+}$donors in the absence of insulitis. We also show that, on average, double-aAb ${ }^{+}$donors exhibit larger islet HA deposits than those positive for a single aAb. These observations reveal that islet immune-cell infiltrates are not required for initial islet HA deposition, and that islet HA deposits expand along with increasing number of islet aAbs, which indicates progression of autoimmunity. It is important to point out that both the largest islet HA deposits and insulitis were observed in the double-aAb ${ }^{+}$donors who carried the highly susceptible HLA genotype and were under 40 years of age. Essentially, all individuals with multiple islet aAbs subsequently progress to clinically overt diabetes [35]. Although progression to clinical onset of diabetes occurs at different rates, we suggest that the seven $\mathrm{aAb}^{+}$donors exhibiting prominent HA deposits were in a stage of rapid progression of the pathogenetic process.

In presymptomatic DRLyp/Lyp rats, initial islet HA deposition predates the appearance of insulitic cells. This finding, together with our observation of islet HA deposits in the absence of islet immune-cell infiltrates in $\mathrm{aAb}^{+}$donors, indicates that the process of HA accumulation in islets can occur independently of, and prior to, insulitis. To what extent this accumulation would have eventually contributed to the development of insulitis in the subset of single- $\mathrm{AAb}^{+}$donors with islet HA deposits, had they lived longer, is not possible to determine. Nonetheless, these results suggest that the formation of islet HA deposits may be a prerequisite for the initial adhesion of insulitic cells and subsequent infiltration of islets and, thus, could potentially be considered causal. Support for an HA-insulitis causal relationship comes from in vitro studies that indicated that an HA-rich ECM, generated by activated human fibroblasts, endothelial or smooth muscle cells, controls the migration of human mononuclear leukocytes $[34,36,37]$. Also, our observations in BB rats are in line with the finding that HA accumulation precedes the inflammatory infiltrate in the intestinal mucosa in mice with induced experimental colitis [38].

We point out a relationship between the extensiveness of islet HA accumulation and the degree of insulitis since, in BB rats, the amount of islet HA staining positively correlates with the continuum of insulitis, from inaugural to invasive. Immune cells were first observed in the islets of 7-8-week old DRLyp/Lyp rats in which islet HA-stained areas had increased 2.4-fold, on average, vs younger rats. Also, in both humans and BB rats, the immune-cell infiltrates were situated within the largest HA accumulations in islets. These findings indicate that the precursory islet HA build-up may determine the sites of subsequent immune-cell entry into islets and that insulitis initiates in islets that have accumulated a 'critical' mass of HA. Additional islet HA deposition was concurrent with expansion of insulitic infiltrates inside islets, which suggests that the continuous amassment of HA may also influence the advancement of insulitis.

While the initial HA accumulation was not associated with a significant reduction in beta cell mass, the DRLyp/Lyp rats with HA-abundant deposits and grade 1 insulitis exhibited a considerable loss of beta cells. The consequences of HA deposition on beta cell survival remain to be determined. In the presence of insulitis, it is difficult to dissect the impact of the accumulated HA from that of the immune cells [12, 39-41]. However, it can be speculated that changes in islet ECM properties, conferred by continual HA deposition, might affect beta cell viability via HAinduced signalling pathways and cellular responses in islets. Also, in synergy with the insulitic cells and secreted cytokines, abundant HA may create an inflammatory microenvironment that is detrimental to beta cells.

Human islets with abundant HA were not localised in specific parts of the human pancreas and their uneven distribution is reminiscent of the 'patchy' pattern of insulitis described in type 1 diabetes $[1,9,11]$. We previously found a similar distribution pattern of HA-rich islets and insulitis in 


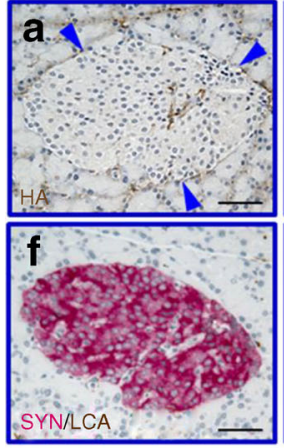

Insulitis grade 0
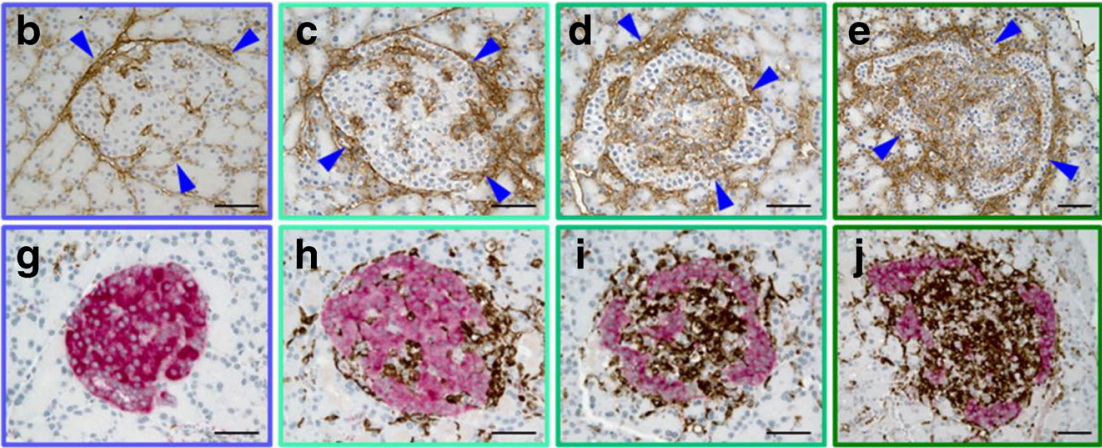

Insulitis grade 0
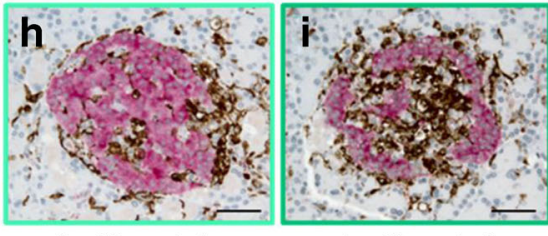

Insulitis grade 2

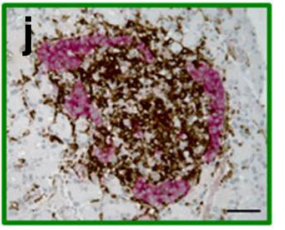

Insulitis grade 3

\section{$\mathbf{k}$}

Rat age (weeks)

DRLyp/+

DRLyp/Lyp

$6-12$

7-8

Islet $\mathrm{HA}^{+}$area

$\left(\mu \mathrm{m}^{2}\right)$
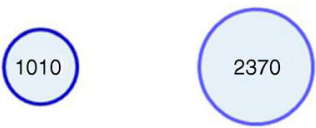

Per cent islets with

$\mathrm{HA}^{+}$areas
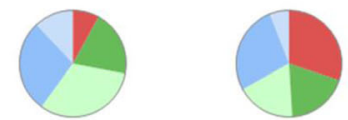

Per cent islets

with insulitis

Insulitis grade
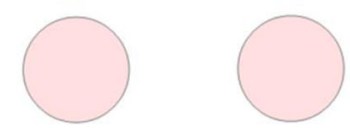

0

0

Beta cell mass

$(\mu \mathrm{g})$
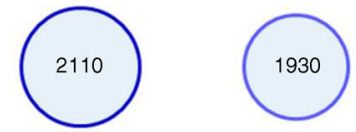

Islet $\mathrm{HA}^{+}$area $\left(\mu \mathrm{m}^{2}\right)$ size category

$\begin{array}{llllll}0 & 100 & 500 & 1000 & 2000 & 28,000\end{array}$

Fig. 7 Islet HA accumulation precedes insulitis in presymptomatic $\mathrm{DR} L y p / L y p$ rats. (a-e) HA staining (brown) in islets from (a) diabetesresistant DRLyp/+ and (b-e) diabetes-prone DRLyp/Lyp rats. Arrowheads point to the islet border. (f-j) SYN (red) staining of islets from (f) $\mathrm{DR} L y p /+$ and $(\mathbf{g}-\mathbf{j})$ DRLyp/Lyp rats. Scale bars, $50 \mu \mathrm{m}$. (k) Islet $\mathrm{HA}^{+}$ areas (mean in 300-400 islets/group), islet $\mathrm{HA}^{+}$area size distribution,

tissues from donors with type 1 diabetes [17]. These observations were reproduced in prediabetic and diabetic BB rats in the present study, in which the location of the largest islet HA deposits served as a blueprint for islet immune-cell infiltration. The complete overlap in the localisation of islets highly enriched in HA and insulitis reinforces their close relationship, which, from initially being potentially causative, might have progressed into an interdependent partnership.

In conclusion, this study indicates that islet HA accumulation is an early event in the pathogenesis of autoimmune diabetes. Our novel observations, remarkably

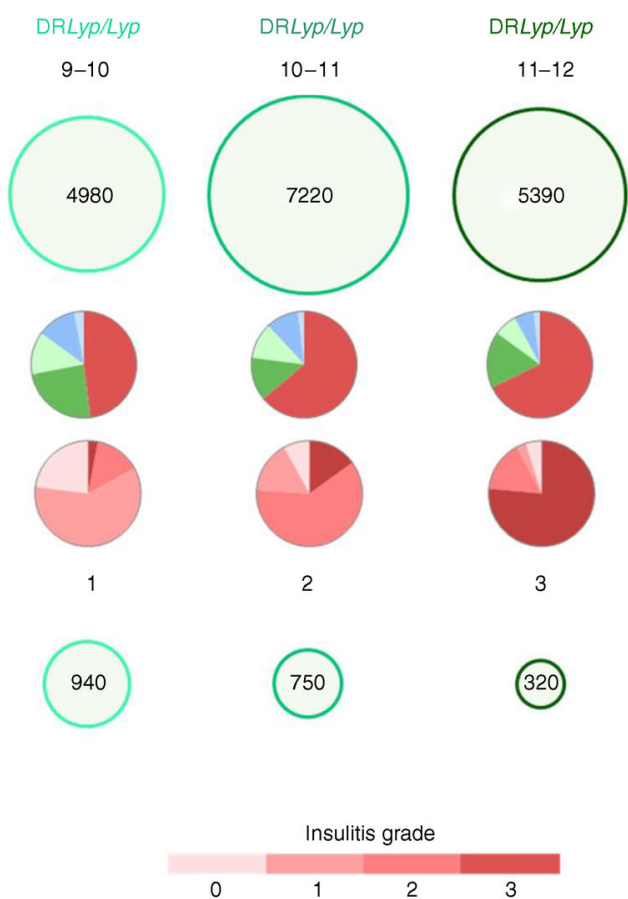

insulitis and beta cell mass in DRLyp/+ and DRLyp/Lyp rats. For 'islet $\mathrm{HA}^{+}$area' and 'beta cell mass', the size of each circle is proportional to the mean value, which is indicated within the circle. The pie charts represent the percentage of islets with $\mathrm{HA}^{+}$areas falling within each of the HA area size categories or the proportion of islets with insulitis grade $0,1,2$ or 3 in the rats within each age group (see ESM Table 3 for further details) consistent in both humans with ongoing islet autoimmunity and diabetes-prone BB rats in the preclinical stage of the disease, support our proposal of a crucial role of islet HA in the inception and promotion of islet inflammation in type 1 diabetes [16]. Therefore, additional studies are warranted to explore the underlying mechanisms that regulate HA mass in islets and the interactions between HA and islet cells or immune cells. Clarifying these molecular mechanisms will be important in developing therapeutic interventions that target HA accumulation with the aim to stop the development of insulitis. 
Acknowledgements This research was performed with the support of the Network for Pancreatic Organ Donors with Diabetes (nPOD), a collaborative type 1 diabetes research project sponsored by JDRF. Organ procurement organisations partnering with $\mathrm{nPOD}$ to provide research resources are listed at www.jdrfnpod.org/for-partners/npod-partners/. We thank V. M. Green (Benaroya Research Institute, Seattle, WA, USA) for editing the manuscript.

Data availability The data are available on request from the corresponding author.

Funding This study was supported by the Leona M. and Harry B. Helmsley Charitable Trust George S. Eisenbarth nPOD Award for Team Science to MB and TNW (2015PG T1D052) and by a Pilot Project to MB from the NIAID Cooperative Study Group for Autoimmune Disease Prevention Innovative Study (U01 AI101990). National Institutes of Health National Institute of Diabetes and Digestive and Kidney Diseases grant P30-DK-17047 to University of Washington Diabetes Research Center Imaging and Cell Function Analysis Core provided core support. ÅL was supported by the Swedish Research Council and the Diabetesfonden.

Duality of interest The authors declare that there is no duality of interest associated with this manuscript.

Contribution statement $\mathrm{MB}$ conceived the project, designed and performed the experiments, collected and analysed the data, and wrote the manuscript. PYJ, MJD, AJD, ÅL and TNW contributed to data acquisition. MJL contributed to experimental procedures. CS and CJG contributed to data analysis. CS and CJG contributed to writing the manuscript. All authors have reviewed and approved the final version of the manuscript. MB is the guarantor of this work.

\section{References}

1. Atkinson MA, Eisenbarth GS, Michels AW (2014) Type 1 diabetes. Lancet 383(9911):69-82. https://doi.org/10.1016/S0140-6736(13) 60591-7

2. Eisenbarth GS (1986) Type I diabetes mellitus. A chronic autoimmune disease. N Engl J Med 314(21):1360-1368. https://doi.org/ 10.1056/NEJM198605223142106

3. Insel RA, Dunne JL, Atkinson MA et al (2015) Staging presymptomatic type 1 diabetes: a scientific statement of JDRF, the Endocrine Society, and the American Diabetes Association. Diabetes Care 38(10):1964-1974. https://doi.org/10.2337/dc151419

4. Couper JJ, Haller MJ, Greenbaum CJ et al (2018) ISPAD Clinical Practice Consensus Guidelines 2018: stages of type 1 diabetes in children and adolescents. Pediatr Diabetes 19(Suppl 27):20-27. https://doi.org/10.1111/pedi.12734

5. Bingley PJ, Bonifacio E, Williams AJ, Genovese S, Bottazzo GF, Gale EA (1997) Prediction of IDDM in the general population: strategies based on combinations of autoantibody markers. Diabetes 46(11):1701-1710. https://doi.org/10.2337/diab.46.11. 1701

6. Gorus FK, Keymeulen B, Veld PA, Pipeleers DG (2013) Predictors of progression to type 1 diabetes: preparing for immune interventions in the preclinical disease phase. Expert Rev Clin Immunol 9(12):1173-1183. https://doi.org/10.1586/1744666X.2013.856757

7. Ziegler AG, Rewers M, Simell O et al (2013) Seroconversion to multiple islet autoantibodies and risk of progression to diabetes in children. JAMA 309(23):2473-2479. https://doi.org/10.1001/jama. 2013.6285
8. Wherrett DK, Chiang JL, Delamater AM et al (2015) Defining pathways for development of disease-modifying therapies in children with type 1 diabetes: a consensus report. Diabetes Care 38(10): 1975-1985. https://doi.org/10.2337/dc15-1429

9. Gepts W (1965) Pathologic anatomy of the pancreas in juvenile diabetes mellitus. Diabetes 14(10):619-633. https://doi.org/10. 2337/diab.14.10.619

10. Pipeleers D, Ling Z (1992) Pancreatic beta cells in insulindependent diabetes. Diabetes Metab Rev 8(3):209-227. https:// doi.org/10.1002/dmr.5610080303

11. In't Veld P (2011) Insulitis in human type 1 diabetes: the quest for an elusive lesion. Islets 3(4):131-138. https://doi.org/10.4161/is1.3.4. 15728

12. Roep BO (2003) The role of T cells in the pathogenesis of type 1 diabetes: from cause to cure. Diabetologia 46(3):305-321. https:// doi.org/10.1007/s00125-003-1089-5

13. Coppieters KT, Dotta F, Amirian N et al (2012) Demonstration of islet-autoreactive CD8 T cells in insulitic lesions from recent onset and long-term type 1 diabetes patients. J Exp Med 209(1):51-60. https://doi.org/10.1084/jem.20111187

14. Campbell-Thompson M, Fu A, Kaddis JS et al (2016) Insulitis and $\beta$-cell mass in the natural history of type 1 diabetes. Diabetes 65(3): 719-731. https://doi.org/10.2337/db15-0779

15. Morgan NG, Richardson SJ (2018) Fifty years of pancreatic islet pathology in human type 1 diabetes: insights gained and progress made. Diabetologia 61(12):2499-2506. https://doi.org/10.1007/ s00125-018-4731-y

16. Bogdani M (2016) Thinking outside the cell: a key role for hyaluronan in the pathogenesis of human type 1 diabetes. Diabetes 65(8):2105-2114. https://doi.org/10.2337/db15-1750

17. Bogdani M, Johnson PY, Potter-Perigo S et al (2014) Hyaluronan and hyaluronan-binding proteins accumulate in both human type 1 diabetic islets and lymphoid tissues and associate with inflammatory cells in insulitis. Diabetes 63(8):2727-2743. https://doi.org/10. 2337/db13-1658

18. Laurent TC, Laurent UB, Fraser JR (1996) The structure and function of hyaluronan: an overview. Immunol Cell Biol 74(2):A1-A7. https://doi.org/10.1038/icb.1996.32

19. Petrey AC, de la Motte CA (2014) Hyaluronan, a crucial regulator of inflammation. Front Immunol 5:101. https://doi.org/10.3389/ fimmu.2014.00101

20. Wang A, de la Motte C, Lauer M, Hascall V (2011) Hyaluronan matrices in pathobiological processes. FEBS J 278(9):1412-1418. https://doi.org/10.1111/j.1742-4658.2011.08069.x

21. Mordes JP, Bortell R, Blankenhorn EP, Rossini AA, Greiner DL (2004) Rat models of type 1 diabetes: genetics, environment, and autoimmunity. ILAR J 45(3):278-291. https://doi.org/10.1093/ilar.45.3.278

22. Fuller JM, Bogdani M, Tupling TD et al (2009) Genetic dissection reveals diabetes loci proximal to the gimap5 lymphopenia gene. Physiol Genomics 38(1):89-97. https://doi.org/10.1152/ physiolgenomics.00015.2009

23. Bogdani M, Henschel AM, Kansra S et al (2013) Biobreeding rat islets exhibit reduced antioxidative defense and $\mathrm{N}$-acetyl cysteine treatment delays type 1 diabetes. J Endocrinol 216(2):111-123. https://doi.org/10.1530/joe-12-0385

24. Toole BP, Yu Q, Underhill CB (2001) Hyaluronan and hyaluronanbinding proteins. Probes for specific detection. Methods Mol Biol 171:479-485. https://doi.org/10.1385/1-59259-209-0:479

25. Hellman B, Angervall L (1961) The frequency distribution of the number and volume of the islets of Langerhans in man: studies in diabetes of early onset, insuloma and acromegaly. Acta Pathol Microbiol Scand 53:230-236. https://doi.org/10.1111/j.16990463.1961.tb00405.x

26. Kim A, Miller K, Jo J, Kilimnik G, Wojcik P, Hara M (2009) Islet architecture: a comparative study. Islets 1(2):129-136. https://doi. org/10.4161/isl.1.2.9480 
27. Campbell-Thompson ML, Atkinson MA, Butler AE et al (2013) The diagnosis of insulitis in human type 1 diabetes. Diabetologia 56(11):2541-2543. https://doi.org/10.1007/s00125-013-3043-5

28. Ziegler AG, Nepom GT (2010) Prediction and pathogenesis in type 1 diabetes. Immunity 32(4):468-478. https://doi.org/10.1016/j. immuni.2010.03.018

29. Redondo MJ, Geyer S, Steck AK et al (2018) A type 1 diabetes genetic risk score predicts progression of islet autoimmunity and development of type 1 diabetes in individuals at risk. Diabetes Care 41(9):1887-1894. https://doi.org/10.2337/dc18-0087

30. Concannon P, Rich SS, Nepom GT (2009) Genetics of type 1A diabetes. N Engl J Med 360(16):1646-1654. https://doi.org/10. 1056/NEJMra0808284

31. Noble JA, Erlich HA (2012) Genetics of type 1 diabetes. Cold Spring Harb Perspect Med 2(1):a007732. https://doi.org/10.1101/ cshperspect.a007732

32. Jiang D, Liang J, Noble PW (2011) Hyaluronan as an immune regulator in human diseases. Physiol Rev 91(1):221-264. https:// doi.org/10.1152/physrev.00052.2009

33. Mummert ME (2005) Immunologic roles of hyaluronan. Immunol Res 31(3):189-206. https://doi.org/10.1385/IR:31:3:189

34. Evanko SP, Potter-Perigo S, Bollyky PL, Nepom GT, Wight TN (2012) Hyaluronan and versican in the control of human Tlymphocyte adhesion and migration. Matrix Biol 31(2):90-100. https://doi.org/10.1016/j.matbio.2011.10.004

35. Bingley PJ, Boulware DC, Krischer JP, the Type 1 Diabetes TrialNet Study Group (2016) The implications of autoantibodies to a single islet antigen in relatives with normal glucose tolerance: development of other autoantibodies and progression to type 1 diabetes. Diabetologia 59(3):542-549. https://doi.org/10.1007/ s00125-015-3830-2
36. de La Motte CA, Hascall VC, Calabro A, Yen-Lieberman B, Strong SA (1999) Mononuclear leukocytes preferentially bind via CD44 to hyaluronan on human intestinal mucosal smooth muscle cells after virus infection or treatment with poly(I.C). J Biol Chem 274(43): 30747-30755

37. Lauer ME, Mukhopadhyay D, Fulop C, de la Motte CA, Majors AK, Hascall VC (2009) Primary murine airway smooth muscle cells exposed to poly $(\mathrm{I}, \mathrm{C})$ or tunicamycin synthesize a leukocyteadhesive hyaluronan matrix. J Biol Chem 284(8):5299-5312. https://doi.org/10.1074/jbc.M807965200

38. Kessler S, Rho H, West G, Fiocchi C, Drazba J, de la Motte C (2008) Hyaluronan (HA) deposition precedes and promotes leukocyte recruitment in intestinal inflammation. Clin Transl Sci 1(1):5761. https://doi.org/10.1111/j.1752-8062.2008.00025.x

39. Delaney CA, Pavlovic D, Hoorens A, Pipeleers DG, Eizirik DL (1997) Cytokines induce deoxyribonucleic acid strand breaks and apoptosis in human pancreatic islet cells. Endocrinology 138(6): 2610-2614. https://doi.org/10.1210/endo.138.6.5204

40. Eizirik DL, Mandrup-Poulsen T (2001) A choice of death-the signal-transduction of immune-mediated beta-cell apoptosis. Diabetologia 44(12):2115-2133. https://doi.org/10.1007/ s001250100021

41. Pinkse GG, Tysma OH, Bergen CA et al (2005) Autoreactive CD8 $T$ cells associated with beta cell destruction in type 1 diabetes. Proc Natl Acad Sci U S A 102(51):18425-18430. https://doi.org/10. 1073/pnas.0508621102

Publisher's note Springer Nature remains neutral with regard to jurisdictional claims in published maps and institutional affiliations. 